\title{
Results of Mitral Valve Surgery with Pulmonary Arterial Hypertension: Analysis of a Retrospective Study
}

Soumaia Bendjaballah*, Redha Lakehal, Farid Aimar, Rabeh Bouharraga and Abdelmalek Bouzid

Department of Cardiology, EHS Djeghri Mokhtar, Constantine, Algeria

\section{Abstract}

Introduction: Rheumatic heart diseases are redoubtable complication of acute articular rheumatic. Without treatment, pulmonary hypertension and right heart failure may occur. This pulmonary hypertension was admitted as predictor of worse outcome after surgery. The aim of our study is to value the results after mitral surgery in patients with moderate and severe pulmonary hypertension.

Methods: This is an observational descriptive retrospective study between January 2006 and December 2012; a total of 201 patients were operated for mitral or mitro-tricuspid disease with pulmonary arterial hypertension in "Djeghri Mokhtar" hospital. These patients are divided into two groups according to preoperative pulmonary hypertension (PAH) degree: (Group A: 102 patients in moderate PAH, $40 \leq$ sPAP<60 mmHg; Group B: 99 patients in severe PAH, Spap $\geq 60 \mathrm{mmHg}$ ). In our study, SPAP was measured with doppler echocardiography. Preoperative, operative and postoperative data collection included age, sex, functional class, type of surgery and cardiopulmonary bypass. Pulmonary arterial systolic pressure, left atrial diameter, left ventricular end-diastolic diameter, and left ventricular ejection fraction were recorded and compared.

Results: The follow up is in mean of 61.73 months (from 30 to 108 months). The functional class was improved in majority of patients. There is a significant decrease in mean SPAP during follow up:(48.72 \pm 5.85 versus $29.12 \pm$ $8.29 \mathrm{mmHg}$ in group $A ; 77.90 \pm 15.62$ versus $28.87 \pm 10.61 \mathrm{mmHg}$ in group B). Global hospital mortality is $0.49 \%$ $(0 \%$ in group $A, 0.98 \%$ in group $B)$. Late mortality is $2.48 \%$ ( $3.92 \%$ in group $A ; 1.01 \%$ in group $B)$. Survival at 05 years is $96.5 \%$.

Conclusion: Pulmonary arterial systolic pressure decreased near normal value in most patients after surgery. Severe pulmonary hypertension must not be an absolute contraindication for mitral surgery, the outcome has been improved by developing cardiopulmonary bypass, myocardial protection and anesthetic technique.

Keywords: Rheumatic heart diseases; Pulmonary arterial hypertension; valvulopathy

\section{Introduction}

Acute rheumatic fever (RAA) has become exceptional in industrialized countries; conversely, it remains a very common disease in developing countries, a real public health problem.

The diagnosis of RAA is relatively simple and confusing, initial angina often goes unnoticed and joint symptoms can be neglected, especially in countries with little medical care, heart attacks (ultimate complications of RAA) may be delayed, long after their constitution and are responsible for most of the deaths observed during the course of the disease.

In left valvulopathies (mitral stenosis +++ ), pulmonary arterial pressure is closely related to the left ventricular filling gene. The repercussion of an increase in left atrial pressure on pulmonary arterial pressure varies according to its importance and its duration of evolution.

Pulmonary arterial hypertension (PAH) has been recognized as an obvious predictive factor of poor postoperative outcome in patients undergoing mitral valvulopathy. Mortality has been estimated (in older studies) in excess of $31 \%$ [1], and as a result many surgeons refused to operate these high-risk patients. Currently, new studies on larger cohorts of patients attempt to prove the opposite and publish excellent results after surgical treatment of this category of patients.

Many questions on this subject seek an answer:

1. What are the preoperative predictors of PAH?

2. Does the presence of PAH affect surgical mortality and postoperative morbidity on the mitral valve?
3. What is the long-term survival after mitral surgery in patients with moderate or severe preoperative $\mathrm{PAH}$ ?

4. Are lung pressures subsequently regressing after surgery, improving the quality of life of the patient or is it the opposite?

The objective of our study is to evaluate the results after mitral surgery in patients with severe and moderate $\mathrm{PAH}$ and to try, by referring to recent international publications, to answer the questions previously asked.

\section{Materials and Methods}

It is a retrospective descriptive observational study of 201 cases of patients operated for advanced mitral or mitro-tricuspid valvulopathy, at the stage of moderate or severe pulmonary arterial hypertension, during a period extending from January 2006 to December 2012.

Our study has set itself as inclusion criteria:

*Corresponding author: Soumaia Bendjaballah, Department of Cardiology, EHS Djeghri Mokhtar, Constantine, Algeria, Tel: 36.3558349, 6.6533211; E-mail: bendjaballahs@yahoo.fr

Received July 25, 2017; Accepted August 31, 2017; Published September 05 2017

Citation: Bendjaballah S, Lakehal R, Aimar F, Bouharraga R, Bouzid A (2017) Results of Mitral Valve Surgery with Pulmonary Arterial Hypertension: Analysis of a Retrospective Study. J Cardiovasc Dis Diagn 5: 292. doi: 10.4172/23299517.1000292

Copyright: $(2017$ Bendjaballah S, et al. This is an open-access article distributed under the terms of the Creative Commons Attribution License, which permits unrestricted use, distribution, and reproduction in any medium, provided the original author and source are credited. 
Patients with mitral rheumatic etiology Mitral stenosis (MS), Mitral insufficiency (MI), Mitral Disease (MM)), or mitro-tricuspid in moderate PAH $(40 \leq$ PAPS $<60 \mathrm{mmHg})$ or Severe (PAPS $\geq 60 \mathrm{mmHg}$ ).

Reoperations: patients with a history of open-heart mitral commissurotomy (CMCO), mitral valve replacement (MVR), or aortic valve replacement (AOVR) with rheumatic mitral lesion leading to moderate or severe PAH.

Patients recruited for the consultation and supported by the same team of cardiologists (preoperative), the echocardio-doppler control was performed by private cardiologists. Patients operated in our center according to the same protocol and surgical team. Operative procedure on the mitral valve associated or not with a gesture on the tricuspid valve.

We excluded from our study: Patients with associated aortic valvulopathy, degenerative and dystrophic MI, ischemic MI, patients with chronic obstructive pulmonary disease. Associated coronary artery disease, primary PAH, systemic arterial hypertension $(>140 / 90$ $\mathrm{mmHg}$ ) congestive heart failure, renal impairment (serum creatinine $\geq$ $2 \mathrm{mg} / \mathrm{dl}$ ), Hepatic dysfunction (serum bilirubin $\geq 3 \mathrm{mg} / \mathrm{dl}$ ).

In response to these criteria, 201 files were selected and were subdivided into two groups based on the value of systolic pulmonary artery pressure (sPAP) evaluated by echocardiography-doppler:

Group A: with moderate PAH: sPAP: $40 \leq$ PAPS $<60 \mathrm{mmHg}(102$ patients)

Group B: with severe PAH: sPAP $\geq 60 \mathrm{mmHg}$ (99 patients)

All of these patients were cared for by the same team of cardiologists, surgeons and anesthetists; they were all operated by vertical median sternotomy under extracorporeal circulation (CEC) in normothermia.

\section{Results}

In this study, all patients had rheumatic mitral valvulopathy. The retrospective analysis of the cases allowed us to distinguish two groups paired, this parity is found for the majority of preoperative variables especially age, sex, geographic origin, functional stage, presence of atrial fibrillation

The number of NYHA stage II and III patients was 78 (76.47\%) and $16(15.68 \%)$ in group A and $69(69.69 \%)$ and $19(19.19 \%)$ in Group B respectively (Table 1).

The duration of symptomatic change varied significantly between the two groups with an average of $4.25 \pm 5.16$ years in group $A$ and 6.31 \pm 7.09 years in group B (Table 1 ).

Mitral valvulopathy varied in the two groups between tight MS, (MS+MI), MI, mitral restenosis, mitral prosthesis desinsertion and mitral bioprosthesis dysfunction (Table 2).

Tricuspid regurgitation grade III to IV was found in 19 (18.62\%) Group A patients and 48 (48.48\%) Group B patients.

Preoperative transthoracic doppler echocardiography was performed in all patients, systolic pulmonary arterial pressure (sPAP), left atrium diameter (LAD), left ventricular end-diastastolic diameter (LVEDD), left ejection fraction (LEF), were evaluated and compared. sPAP varied between $40 \mathrm{mmHg}$ and $59 \mathrm{mmHg}$ in group A and between 60 and $140 \mathrm{mmHg}$ in group B. Per and postoperative data included intervention type, duration of cardiopulmonary bypass (CPB) and aortic clamping (AC), use of positive inotropes, number of patients transfused, duration of ventilation and stay in the intensive care unit

\begin{tabular}{|c|c|c|c|}
\hline Characteristics & Group A & Group B & $\mathbf{P}$ \\
\hline Age $(y)$ & $44.25 \pm 12.51$ & $42.61 \pm 12.04$ & 0.345 \\
\hline $\operatorname{Sex}(M / F)(n)$ & $22 / 80$ & $23 / 76$ & 0.77 \\
\hline Weight (kg) & $63.93 \pm 14.94$ & $62.35 \pm 12.28$ & 0.41 \\
\hline $\begin{array}{l}\text { Preoperative atrial } \\
\text { fibrillation }(n)\end{array}$ & 45 & 51 & 0.29 \\
\hline Nyha II (n) & 78 & 69 & -- \\
\hline Nyha III (n) & 16 & 19 & -- \\
\hline Nyha IV (n) & 0 & 3 & -- \\
\hline $\begin{array}{l}\text { Duration of evolution } \\
\text { (years) }\end{array}$ & $4.25 \pm 5.16$ & $6.31 \pm 7.09$ & $<0.05$ \\
\hline $\mathrm{LAD}(\mathrm{mm})$ & $53.49 \pm 10.11$ & $56.87 \pm 9.99$ & $<0.05$ \\
\hline LVEDD (mm) & $52.83 \pm 8.59$ & $47.82 \pm 8.27$ & $<0.05$ \\
\hline LVESD (mm) & $36.30 \pm 6.17$ & $33.10 \pm 6.11$ & $<0.05$ \\
\hline LVEF (\%) & $58.21 \pm 6.44$ & $58.16 \pm 7.52$ & 0.95 \\
\hline Aortic clamping (min) & $50.57 \pm 14.46$ & $50 \pm 14.56$ & 0.77 \\
\hline CPB (min) & $68.39 \pm 18.08$ & $66.18 \pm 15.84$ & 0.35 \\
\hline $\begin{array}{c}\text { Inotropic (frequency of } \\
\text { use \%) }\end{array}$ & 36.27 & 46.46 & 0.08 \\
\hline $\begin{array}{l}\text { Transfusion (number of } \\
\text { patients) }\end{array}$ & 60 & 55 & 0.24 \\
\hline Ventilation (hours) & $10.65 \pm 5.84$ & $10.86 \pm 4.90$ & 0.78 \\
\hline Stay in ICU (Days) & $2.27 \pm 0.73$ & $2.42 \pm 1.23$ & 0.29 \\
\hline Hospital stay (Days) & $12.44 \pm 5.35$ & $12.63 \pm 6.41$ & 0.8 \\
\hline Operative mortality & 0 & 0 & -- \\
\hline
\end{tabular}

Table 1: Data of group A and B.

\begin{tabular}{|c|c|c|}
\hline Mitral lesion & Group A & Group B \\
\hline MS & $17(16.67 \%)$ & $40(40.40 \%)$ \\
\hline MR & $18(17.65 \%)$ & $5(5.05 \%)$ \\
\hline MS+MR & $52(50.98 \%)$ & $46(46.46 \%)$ \\
\hline Mitral restenosis & $14(13.73 \%)$ & $6(6.06 \%)$ \\
\hline Desinsertion of mitral prothesis & $1(0.98 \%)$ & $0 \%$ \\
\hline Mitral bioprosthesis dysfunction & $0 \%$ & $2(2.02 \%)$ \\
\hline
\end{tabular}

Table 2: Preoperative mitral lesions.

\begin{tabular}{|c|c|c|}
\hline Gestures on the mitral valve & Group A & Group B \\
\hline Commissurotomy & $2(1.96 \%)$ & $3(3.03 \%)$ \\
\hline Mechanical MVR & $95(93.14 \%)$ & $92(92.92 \%)$ \\
\hline Biological MVR & $4(3.93 \%)$ & $4(4.04 \%)$ \\
\hline Reinsertion of MV & $1(0.98 \%)$ & $00 \%$ \\
\hline
\end{tabular}

Table 3: Gestures on the mitral valve.

(IUC); We did not find any significant difference between the two groups (Table 1).

The surgical procedure consisted of a mitral monograft in 81 (79.41\%) patients in group A and $46(46.46 \%)$ patients in group B and a double mitro-tricuspid gesture in 21 (20.58\%) and 53 (53.53\%) patients in groups A and B respectively. At the mitral valve, the surgical gesture varied between MVR (essentially mechanical), commissurotomy and mitral valve reinsertion (Table 3 ). In the tricuspid valve, a DE VEGA type annuloplasty was performed in $20(19.60 \%)$ of Group A patients and $50(50.50 \%)$ of Group B patients; an annuloplasty of key in 2 patients of group B.

Some complications occurred in ICU represented mainly by mediastinal bleeding in 06 patients in group A and 04 in group B. Global early mortality was $0.49 \%$, one patient in group B who died on day 40 due to renal insufficiency.

Analysis of medium-term results revealed a significant decline in PAPS between pre- and postoperative; in group A, the mean PAPS 
decreased by $48,66 \mathrm{mmHg} \pm 5.80 \mathrm{mmHg}$ at $37.37 \mathrm{mmHg} \pm 9.60 \mathrm{mmHg}$; As well as in group B patients, PAPS dropped from $77.60 \mathrm{mmHg} \pm 15.60$ $\mathrm{mmHg}$ to $40.50 \mathrm{mmHg} \pm 12.76 \mathrm{mmHg}$. In the long term and after a follow-up of 30 months to 108 months ( $\approx 05$ years on average), we noted an improvement in the functional stage with an improved quality of life, 95 (96.94\%) and 97 (100\%) of patients in Groups A and B respectively are in Stage I or II of the NYHA; 3 patients in group A remain in stage III of the NYHA (Tables 4 and 5).

For echocardiographic parameters, there was a significant decrease in LAD in both groups with decreased LVEDD especially in group A patients $(\mathrm{p}<0.05)$ and stabilization in the Group B patients; the LEF at the control did not undergo a significant change $(\mathrm{P}=0.16)$ in both groups (Tables 4 and 5). As regards the sPAP, and at Group A level, there is a clear regression of this; It decreased from $48.72 \mathrm{mmHg} \pm 5.85 \mathrm{mmHg}$ preoperatively to $29.12 \pm 8.29$ at patient control $(\mathrm{P}<0.05)$ (Figure 1$)$. It should be noted that the SPAP regression did not concern all patients in this group; In fact, 13 patients had moderate persistent PAH with a sPAP at the control oscillating between 40 and $47.3 \mathrm{mmHg}$. In group B, there was also a significant decline of sPAP between preoperative (77.90 $\mathrm{mmHg} \pm 15.62 \mathrm{mmHg})$ and control $(28.87 \mathrm{mmHg} \pm 10.61 \mathrm{mmHg})$ $(\mathrm{P}<0.05)$ (Figure 1). However, 10 patients maintained moderate $\mathrm{PAH}$ between $40 \mathrm{mmHg}$ and $51.9 \mathrm{mmHg}$; and 02 patients a severe PAH (60 $\mathrm{mmHg}$ and $84 \mathrm{mmHg}$ ).

The total delayed mortality was about $2.48 \%$ (5 patients): 04 (3.92\%) Group A patients who died as a result of stroke (1 patient), heart failure (1 patient). Unknown cause in 2 patients; 1 patient in group B who died of undetermined cause. The overall survival of the two five-year groups was $96.5 \%$ (95.5\% for group A and $97.4 \%$ for group B.) The difference between the two groups was not statistically significant according to Log Rank, $x^{2}=0.89$ (Figure 2).

\begin{tabular}{|c|c|c|c|}
\hline \multirow{2}{*}{ Parameters } & Group A & Group A & \multirow{2}{*}{ P } \\
\cline { 2 - 3 } & (Preoperative) & (Control) & \\
\hline Nyha & -- & -- & -- \\
\hline Nyhal $(\mathrm{n})$ & 8 & 67 & -- \\
\hline Nyhall $(\mathrm{n})$ & 74 & 28 & -- \\
\hline Nyha III $(\mathrm{n})$ & 16 & 3 & -- \\
\hline Nyha IV $(\mathrm{n})$ & 0 & 0 & -- \\
\hline Atrial fibrillation $(\mathrm{n})$ & 44 & 37 & $<0.05$ \\
\hline LAD $(\mathrm{mm})$ & $53.55 \pm 10.27$ & $45.05 \pm 9.43$ & $<0.05$ \\
\hline LVEDD $(\mathrm{mm})$ & $52.72 \pm 8.57$ & $48.62 \pm 7.57$ & $<0.05$ \\
\hline LVESD $(\mathrm{mm})$ & $36.26 \pm 6.11$ & $34.4 \pm 7.04$ & 0.16 \\
\hline LVEF $(\%)$ & $58.06 \pm 6.32$ & $56.68 \pm 8.31$ & 0.37 \\
\hline SPAP $(\mathrm{mm}$ Hg) & $48.72 \pm 5.85$ & $29.12 \pm 8.29$ & $<0.05$ \\
\hline Tann
\end{tabular}

Table 4: Comparison of pre-and postoperative parameters of group $A$.

\begin{tabular}{|c|c|c|c|}
\hline \multirow{2}{*}{ Parameters } & Group B & Group B & \multirow{2}{*}{ P } \\
\cline { 2 - 3 } & Preoperative & Postoperative & \\
\hline Nyha & -- & -- & -- \\
\hline Nyhal (n) & 8 & 71 & -- \\
\hline Nyhall (n) & 67 & 26 & -- \\
\hline Nyha III (n) & 19 & 0 & -- \\
\hline Nyha IV (n) & 3 & 0 & -- \\
\hline Atrial fibrillation (n) & 49 & 53 & -- \\
\hline LAD (mm) & $56.85 \pm 10.08$ & $46.64 \pm 10.46$ & $<0.05$ \\
\hline LVEDD (mm) & $47.65 \pm 8.26$ & $48.95 \pm 6.85$ & 0.1 \\
\hline LVESD (mm) & $33.05 \pm 6.14$ & $33.37 \pm 7.06$ & 0.65 \\
\hline LVEF $(\%)$ & $58.24 \pm 6.97$ & $57.11 \pm 6.75$ & 0.17 \\
\hline PAPS $(\mathrm{mm}$ Hg) & $77.90 \pm 15.62$ & $28.87 \pm 10.61$ & $<0.05$ \\
\hline
\end{tabular}

Table 5: Comparison of the pre-and postoperative parameters of group $B$.

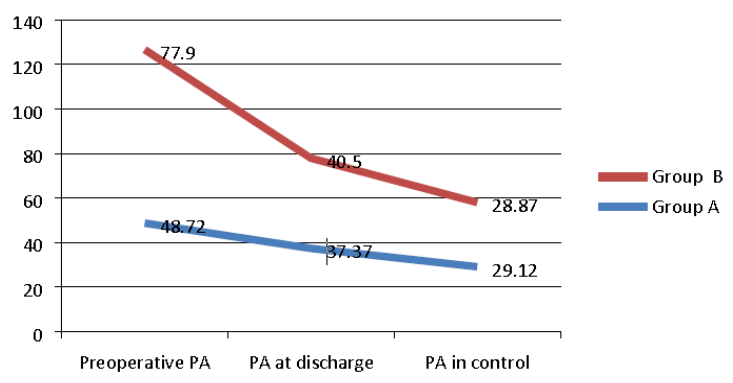

Figure 1: Progressive decrease of mean PA between preoperative, postoperative and control.

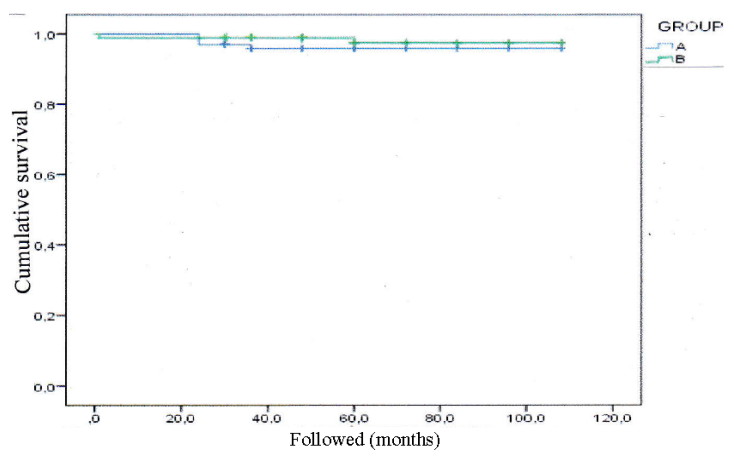

Figure 2: Five years survival curve.

\section{Discussion}

The surgery of rheumatic valvulopathies constitutes the essential part of the operative activity in the services of cardiac surgery of the third world. The valvular lesions are unfortunately already highly evolved, mutilating, leaving little chance for conservative surgery, the patients are of ore and already at a stage of PAH very evolved.

This PAH is a classical pathophysiologic consequence of left heart valvulopathies, and elevated pulmonary pressures result initially from increased left atrial pressure, pulmonary vasoconstriction, and ultimately obliterative changes in the pulmonary vascular bed; excessive thickening of the media and intimal fibrosis of pulmonary arterioles are typical changes following a long course of mitral stenosis [2-4].

Until now, there is no consensus in the literature on the results after surgery for this category of patients; Some studies have associated $\mathrm{PAH}$ with a poor outcome and an estimated high mortality rate of $31 \%$ [1], which has led some authors to consider PAH as an absolute contraindication to MVR [5-9], while others do not fully agree and argue that severe PAH does not imply a greater surgical risk [10-15].

After reviewing subsequent studies that are controversial, it is relevant to reassess the outcome of these patients with the advent of new anesthetic products, modern cardioplegia, improved mitral prostheses and improved postoperative management.

Concerning the reversibility of severe PAH, again the opinions are controversial; some authors claim in their writings that PAH regresses after MVR $[10,11,16,17]$; while others see that severe PAH persists after surgery and is associated with a high risk of right heart failure $[5,18,19]$. In our series, the duration of progression of the heart disease is rather long but different between the two groups $(\mathrm{P}<0.05)$, the symptomatology in the patients of group $\mathrm{B}$ is older, this shows that more the mitral valve disease is evolved, more the PAH is severe. 
Our population is young and predominantly female; the young age of the patients is explained by the rheumatic origin of valvulopathy, which is supported by the various publications $[11,16,20,21]$.

Patients undergoing surgery are for the majority in stage II of the NYHA (76.47\% and $69.69 \%$ in group A and B respectively); In the other series, patients are in stage III or IV [11,16,20-22]. Postoperatively, it is interesting to report an improvement in the quality of life; $68.36 \%$ and $73.19 \%$ of patients in group A and B respectively were in stage I of NYHA ( $\mathrm{P}<0.05$ for both groups).

The arrhythmia was present preoperatively in both groups $(44.12 \%$ and $51.52 \%$, respectively, in patients in groups A and B). In the various studies, preoperative arrhythmia was observed in $84.4 \%, 68 \%$ of patients in Cesnjevar and according to Song [16,21]; atrial fibrillation was found in both groups with severe PAH (56.66\%) and moderate PAH (50\%) [10]. The presence of atrial fibrillation is strongly correlated with the importance of PAH.

Analysis of preoperative and postoperative ultrasound parameters revealed significant changes in many variables after surgical correction. Preoperatively, dilatation of left atrium $>50 \mathrm{~mm}$ occurred in both groups A and B (60.77\% and $72.72 \%$, respectively), but was more pronounced in group $\mathrm{B}(\mathrm{P}<0.05)$ indicating the long course of valvulopathy and the severity of $\mathrm{PAH}$.

After surgery, there was a significant reduction in the diameter of the left atrium for the majority of patients in both groups (Tables 4 and 5 ), regression of the size of the LA or reversibility of the remodeling, were observed after mitral valve surgery and it has been shown that the preoperative LVEF is the only variable closely associated with a postoperative reduction in LA diameter [23-25]. Some authors find a close association between LAD regression and reduction of cardiovascular events $[11,21,23]$. In the literature, the decline in the diameter of the LA was strongly observed after mitral surgery.

LVEDD regressed for group A $(\mathrm{P}<0.05)$ and stabilized for group $B(P=0.10)$ after surgery, this cavitary decrease plays an important role in the regression of the pulmonary pressure which improves later, the right ventricule (RV) function. This regression of the size of the LV was observed in several series [21,26].

The preoperative LVEF function was similar between the two groups $(\mathrm{P}=0.86)$, as well as postoperatively $(\mathrm{P}=0.69)$. After surgery and control, the LVEF of the two groups did not undergo a significant change $(\mathrm{P}=0.16$ for group $\mathrm{A}, \mathrm{P}=0.17$ for group $\mathrm{B})$.

There is a gradual and significant decrease in sPAP between preoperative, postoperative and control. Thus, in group A, mean PAPS dropped from $48.66 \mathrm{mmHg} \pm 5.80 \mathrm{mmHg}$, to $37.37 \mathrm{mmHg} \pm 9.60$ $\mathrm{mmHg}$ postoperatively, and reached $29.12 \mathrm{mmHg} \pm 8.29 \mathrm{mmHg}$ at the follow-up $(\mathrm{P}<0.05)$. For group B, sPAP decreased from $77.60 \mathrm{mmHg} \pm$ $15.60 \mathrm{mmHg}$ to $40.50 \mathrm{mmHg} \pm 12.76 \mathrm{mmHg}$ postoperatively, reaching $28.87 \pm 10.61$ at control. $(\mathrm{P}<0.05)$. Thus, $\mathrm{PAH}$ regresses to normal values after surgery, this reduction often occurs soon after surgery and appears to be related to the sudden drop in left atrium pressure and the reversibility of severe pulmonary vasoconstriction in some patients. The fall in pulmonary arterial resistances often continues later months after surgery [16,27-30].

In the literature, the degradation of the PAPS has been observed by several authors throughout different epochs. Camara [20] found that PAPS regressed from $101 \mathrm{mmHg} \pm 22.4 \mathrm{mmHg}$ to $40.5 \mathrm{mmHg} \pm$ $7.5 \mathrm{mmHg}$ postoperatively. Cesnjevar [16] studied for a period of 30 years, 382 patients in severe PAH. It records a regression of PAPS of
$65 \mathrm{mmHg} \pm 2 \mathrm{mmHg}$ to $46 \mathrm{mmHg} \pm 4 \mathrm{mmHg}$. Deepak [11] evaluated the $\mathrm{PAH}$ regression after surgery in 60 patients divided into two groups (moderate and severe PAH). He found that within 48 hours, sPAP returned to near normal values in patients with severe PAH, and normal values in patients with moderate PAH. Bayat [1] compares 02 groups (severe and moderate $\mathrm{PAH}$ ) from a series of 45 patients; he observed in the "moderate" group a significant reduction in sPAP within 24 hours after surgery, whereas in the "severe" group, the sPAP decreased gradually to be significant after 24 hours. cSong [21] studied the result of a series of 32 patients operated in severe $\mathrm{PAH}$, he noticed a consequent fall in sPAP following surgery (from $101.2 \mathrm{mmHg} \pm 20.3$ $\mathrm{mmHg}$ to $48.1 \mathrm{mmHg} \pm 14,3 \mathrm{mmHg}$ ).

It is important to note that 25 patients (12.43\%) had residual PAH of variable importance. The notion of severe preoperative MI, female sex, ACFA, left atrium dilation and preoperative LV dysfunction are found in the majority of these patients. The incomplete resolution of PAH may be related to pulmonary vasoconstriction reactivity and remodeling in the pulmonary vascular structure.

In the literature, El-Ghoreishi [26] found that in patients with preoperative MI, residual PAH was observed 02 years after surgery in $35 \%$ of patients, regardless of preoperative PAH level. An incomplete improvement in pulmonary pressures after surgery suggests that significant pulmonary vascular disease develops very early in the presence of mitral insufficiency, and therefore a mitral insufficiency management strategy as soon as PAPS exceeds $40 \mathrm{mmHg}$ may improve long-term survival [26].

The tricuspid lesion is present in both groups but is more marked and regurgitant in group $\mathrm{B}(\mathrm{P}<0.05)$, which means that more is severe the PAH, more the tricuspid is leaking $[11,26]$. In addition, $53.53 \%$ of patients in the B group benefited of tricuspid annuloplasty, compared with only $21.56 \%$ of patients in group A $(\mathrm{P}<0.05)$. The correction of the tricuspid insufficiency (TI) suppresses the preload of the RV and thus prevents the occurrence of a RV dysfunction. In the literature, the correction of the tricuspid leak was noted by several authors: the correction of tricuspid was performed in $66.66 \%$ of patients in the "severe PAH" group compared to $36.66 \%$ in the " moderate PAH "; TI was corrected in the other series in $87.5 \%$ [21] and in $11 \%$ [20].

Early mortality in mitral valve surgery without PAH was evaluated at $2-3 \%$. The overall early mortality in our series was $0.45 \%, 0 \%$ in group A and $0.98 \%$ in group B (01 patient), the cause of death is not related to $\mathrm{PAH}$ but related to postoperative renal failure requiring dialysis and digestive haemorrhage complicated with mediastinitis.

In the literature, the rate of early mortality has varied with epochs and progress. Camara [20] reported an early mortality rate of $5.6 \%$. Cesnjevar [16] estimated early mortality in its series to be $13.7 \%$ from 1963 to $1973,8.6 \%$ from 1973 to 1983 and $10.8 \%$ from 1983 to 1998 . In the more recent series, there is a reduction in the mortality rate estimated at $0 \%[1,11]$ and at $3.1 \%[21]$.

In previous publications $[16,20]$, the reported deaths were not related to the severity of $\mathrm{PAH}$, but related to bleeding, embolism (stroke and septicemia due to alterations caused by the $\mathrm{CPB}$, inotropic drugs and antibiotics effective at that time, and heart failure is often blamed in early deaths because the risk of heart decompensation is common in patients with PAH. The decrease in the mortality rate over the decades is related to the improvement of the operative techniques (preservation of the apparatus under a mitral valve avoiding LV dysfunction, prosthesis evolution), myocardial protection and CPB circuits, progress anesthesia and postoperative management. 
Late mortality in our series, and for a follow-up between 30 months and 108 months (61.73 months on average), is $2.48 \%$ (05 patients overall); it was $3.92 \%$ in group A (4 patients): cardiac failure (01 patient), stroke (01 patient), and unknown cause (02 patients); and it was $1.01 \%$ in group B (01 patient), of unknown cause.

The overall survival of the two five-year groups was $96.5 \%$ (95.5\% for group A and $97.4 \%$ for group B.) The difference between the two groups was not statistically significant according to Log Rank, $x^{2}=0.89$

Compared to the other series, the late mortality in our series is among the lowest rates, in fact, Camara [20], in 1988, evaluated late mortality at $7.2 \%$ (06 patients) for a follow-up of 09 months to 10 years; it was related to colon cancer (01 patient); with cardiac cause in 05 patients (right heart failure, rupture of mycotic aortic aneurysm, abdominal haemorrhage); The survival at 05 years is $86 \% \pm 3 \%$ and it is $83 \% \pm 4 \%$ at 10 years.

Cesnjevar [16] who divided his study into 3 decades, estimated the late mortality at $5.77 \%$ from $1963-1973 ; 4.95 \%$ from 1973 to 1983 ; and $3.39 \%$ from 1980 to 1990 . The main causes are thromboembolic, haemorrhagic, endocardial, and reoperation. The survival at 5 years is $60 \%, 70 \%, 75 \%$ in the different decades. The survival at 10 years is $50 \%$, $55 \%$ and $75 \%$ respectively.

Song [21], evaluated it at $0 \%$, survival is $96.9 \%$ for a follow -up of 12 months to 45 months. At the end of our study, and in agreement with recent publications $[1,11,21,22]$, there is a marked improvement in early and late results after mitral surgery in patients with PAH, regardless of severity. The combination of several parameters and the progress achieved in surgery and anesthesia has contributed to the achievement of these results.

In our study, the etiology of valvular involvement was rheumatic, we excluded PAHs from ischemic and degenerative MI with a more reserved prognosis (low LEF, advanced age, impaired vascular fibroelasticity) $[2,26,29]$.

Our patients are young, they differ from the elderly by the absence of comorbidities and vascular remodeling, which may explain our results in part. The advanced functional stage is incriminated in operative morbidity and mortality, and our patients are mostly in stage II of the NYHA. The improvement of surgical techniques, methods of myocardial protection, the advent of cardioplegia and the modernization of anesthesia and postoperative management, the use of positive inotropes are all elements conducive to a good evolution.

We have used, for some patients with residual PAH, difficult to extubate postoperatively, sildenafil which has given excellent results [3133]; we have never used other pulmonary vasodilators (prostaglandins $\mathrm{E} 1, \mathrm{NO}$ ) due to the unavailability of these products in our country.

\section{Study Limit}

The number of patients and the decline from 03 to 09 years remain insufficient to have statistical significance. Evaluation by cardiac Doppler ultrasound may suffer from interobserver variations (several cardiologists).

\section{Conclusion}

Patients with rheumatic mitral valve disease at the surgical stage are young, but unfortunately, they almost always arrive at a very late stage of the disease, when the pulmonary artery pressure is very high, approaching the systemic pressure, thus complicating the outcome of these patients.
However, at the end of our study, conclusion can be drawn and answers can be attributed to the questions asked at the beginning of the presentation.

Thus, early mortality, estimated at $30 \%$ in the 1970 s, improved considerably, reaching $5.6 \%$ in the 1980 s, and $0 \%$ to $0.49 \%$ in recent publications. The decrease in mortality rates over the decades is related to improved surgical techniques, myocardial protection and CBP circuits, progress in anesthesia and postoperative management.

Long-term survival after surgery is evaluated at $96.5 \%$ at 05 years, with an improvement in the quality of life and functional stage of the majority of patients.

Is there really a regression of PAH after surgery? The answer is affirmative: yes, there is a regression or even normalization of the SPAP and this independently of the level of preoperative PAH. This reduction occurs early after surgery and appears to be related to the sudden drop in left atrium pressure and the reversibility of severe pulmonary vasoconstriction accompanying $\mathrm{PAH}$.

However, an incomplete improvement in PAPS values was observed in some patients after surgery, particularly those performed for mitral regurgitation.

Thus, pulmonary vascular disease develops very early in the presence of $\mathrm{MI}$, and $\mathrm{PAH}$ has a known negative prognosis. A sPAP $>50$ $\mathrm{mmHg}$ is associated with a lower postoperative LVEF and a high risk of persistence of $\mathrm{PAH}$ after surgery, which is why a surgical management strategy should be considered as soon as the sPAP reaches $40 \mathrm{mmHg}$ or more.

It is found that residual PAH is strongly correlated with the existence of preoperative mitral regurgitation and that some parameters are predictive factors for this residual postoperative $\mathrm{PAH}$, including: symptoms, duration of pathology, LV dysfunction, LA dilatation, LV dilatation and atrial fibrillation.

The incomplete resolution of PAH may be related to reactive pulmonary vasoconstriction and remodeling in the pulmonary vascular structure, a preoperative elevation of pulmonary vascular resistances (PVR) at catheterization is a significant predictor of residual PAH.

Nevertheless, all recent literature shows a regression or even normalization of the sPAP in $90 \%$ of the patients, in particular the young subjects, with improvement of the quality of life. Thus, we will say "yes", it is necessary to operate patients in moderate or severe PAH because the benefit is incontestable and the results are convincing.

However, it will be necessary to go back to the "primum movens" and say that these rheumatic heart diseases are the translation of the failure of the prevention of acute rheumatic fever and that it will be necessary to review the antirheumatic prevention protocols and evaluate them in daily practice. Finally, it should not be forgotten that we cannot eradicate the acute rheumatic fever without improving the socio-economic level of the populations, and it is better in our context to treat angina with a few hundred dinars than to take charge of a patient to expensive cardiac surgery (a few million dinars) and not without risk.

\section{References}

1. Bayat F, Aghdaii N, Farivar F, Bayat A, Valeshabad AK (2013) Early hemodynamic changes after mitral valve replacement in patients with severe and mild pulmonary artery hypertension. Ann Thorac Cardiovasc Surg 19: 201-206.

2. Patel H, Desai M, Tuzcu EM, Griffin B, Kapadia S (2014) Pulmonary hypertension in mitral regurgitation. J Am Heart Assoc 3: e000748. 
Citation: Bendjaballah S, Lakehal R, Aimar F, Bouharraga R, Bouzid A (2017) Results of Mitral Valve Surgery with Pulmonary Arterial Hypertension: Analysis of a Retrospective Study. J Cardiovasc Dis Diagn 5: 292. doi: 10.4172/2329-9517.1000292

3. Parvathy UT, Rajan R, Georgevich FA (2014) Pulmonary function derangements in isolated or predominant mitral stenosis-Preoperative evaluation with clinicohemodynamic correlation. Interv Med Appl Sci 6: 75-84.

4. Fujimoto $\mathrm{Y}$, Urashima $\mathrm{T}$, Kawachi $\mathrm{F}$, Akaike $\mathrm{T}$, Kusakari $\mathrm{Y}$, et al. (2017) Pulmonary hypertension due to left heart disease causes intrapulmonary venous arterialization in rats. J Thorac Cardiovasc Surg.

5. Barclay RS, Reid JM, Stevenson JG, Welsh TM, McSwan N (1972) Long-term follow-up of mitral valve replacement with Starr-Edwards prosthesis. $\mathrm{Br}$ Heart J 34: 129-133.

6. Ward C, Hancock BW (1975) Extreme pulmonary hypertension caused by mitral valve disease (1975) Natural history and results of surgery. Heart 37:74-78.

7. Kaul TK, Bain WH, Jones JV, Lorimer AR, Thomson RM, et al. (1976) Mitra valve replacement in the presence of severe pulmonary hypertension. Thorax 31: 332-336

8. Jegaden O, Rossi R, Delahaye F, Montagna P, Delaye J, et al. (1991) Mitra valve replacement in severe pulmonary hypertension. Long-term results. Arch Mal Coeur Vaiss 84: 1297-1301.

9. Vincens JJ, Temizer D, Post JR, Edmunds LH, Herrmann HC (1995) Longterm outcome of cardiac surgery in patients with mitral stenosis and severe pulmonary hypertension. Circulation 92: 137-142.

10. Zener JC, Hancock EW, Shumway NE, Harrison DC (1972) Regression of extreme pulmonary hypertension after mitral valve surgery. Am J Cardiol 30: 820-826.

11. Tempe DK, Hasija S, Datt V, Tomar AS, Virmani S, et al. (2009) Evaluation and comparison of early hemodynamic changes after elective mitral valve replacement in patients with severe and mild pulmonary arterial hypertension. J Cardiothorac Vasc Anesth 23: 298-305.

12. Paşaoğlu I, Demircin M, Doğan R, Özmen F, Ersoy U, et al. (1992) Mitral valve surgery in the presence of pulmonary hypertension. Jpn Heart J 33: 179-184.

13. Fawzy ME, Hassan W, Stefadouros M, Moursi M, El Shaer F, et al. (2004) Prevalence and fate of severe pulmonary hypertension in 559 consecutive patients with severe rheumatic mitral stenosis undergoing mitral balloon valvotomy. J Heart Valve Dis 13: 942-948.

14. Alejandro A, Cámara ML, Padró JM, Caralps JM (1996) Long-term results of mitral valve surgery in patients with severe pulmonary hypertension. Ann Thorac Surg 61: 1583-1584.

15. Mubeen M, Singh AK, Agarwal SK, Pillai J, Kapoor S, et al. (2008) Mitral valve replacement in severe pulmonary arterial hypertension. Asian Cardiovasc Thorac Ann 16: 37-42.

16. Cesnjevar RA, Feyrer R, Walther F, Mahmoud FO, Lindemann Y, et al. (1998) High-risk mitral valve replacement in severe pulmonary hypertension-30 year's experience. Eur J Cardiothorac Surg 13: 344-352.

17. Yang B, DeBenedictus C, Watt T, Farley S, Salita A, et al. (2016) The impact of concomitant pulmonary hypertension on early and late outcomes following surgery for mitral stenosis. J Thorac Cardiovasc Surg 152: 394-400.

18. Simonsen S, Forfang K, Andersen A, Efskind L (1974) Hospital mortality after mitral valve replacement. J Intern Med 195: 243-246.

19. Madhavan S, Dutt PG, Thingnam SK, Rohit MK, Jayant A (2015) Perioperative follow-up of patients with severe pulmonary artery hypertension secondary to left heart disease: A single center, prospective, observational study. J Cardiothorac Vasc Anesth 29: 1524-1532.

20. Cámara ML, Aris A, Padró JM, Caralps JM (1988) Long-term results of mitral valve surgery in patients with severe pulmonary hypertension. Ann Thorac Surg 45: 133-136.

21. Song X, Zhang C, Chen X, Chen Y, Shi Q, et al. (2015) An excellent result of surgical treatment in patients with severe pulmonary arterial hypertension following mitral valve disease. J Cardiothorac Surg 10: 70.

22. Enter DH, Zaki A, Duncan BF, Kruse J, Andrei AC, et al. (2016) A contemporary analysis of pulmonary hypertension in patients undergoing mitral valve surgery: Is this a risk factor? J Thorac Cardiovasc Surg 151: 1288-1299.

23. Machado LR, Meneghelo ZM, Le Bihan DC, Barretto RB, Carvalho AC, et al. (2014) Preoperative left ventricular ejection fraction and left atrium reverse remodeling after mitral regurgitation surgery. Cardiovasc Ultrasound 12: 45.

24. Güray Y, Demirkan B, Karan A, Güray Ü, Boyacı A, et al. (2009) Left atria compliance and pulmonary venous flow velocities are related to functional status in patients with moderate-to-severe mitral stenosis. Echocardiography 26: $1173-1178$.

25. Hyllén S, Nozohoor S, Meurling C, Wierup P, Sjögren J (2013) Left atrial reverse remodeling following valve surgery for chronic degenerative mitral regurgitation in patients with preoperative sinus rhythm: Effects on long-term outcome. J Cardiovasc Surg 28: 619-626.

26. Ghoreishi M, Evans CF, DeFilippi CR, Hobbs G, Young CA, et al. (2011) Pulmonary hypertension adversely affects short-and long-term survival after mitral valve operation for mitral regurgitation: Implications for timing of surgery. J Thorac Cardiovasc Surg 142: 1439-1452.

27. Coutinho GF, Antunes MJ (2016) Surgery for mitral stenosis in patients with pulmonary hypertension: How far can we go? J Thorac Cardiovasc Surg 152: 302-303.

28. Magne J, Pibarot P, Sengupta PP, Donal E, Rosenhek R, et al. (2015) Pulmonary hypertension in valvular disease: A comprehensive review on pathophysiology to therapy from the HAVEC Group. JACC: Cardiovascular Imaging 8: 83-99.

29. Goldstone AB, Chikwe J, Pinney SP, Anyanwu AC, Funt SA, et al. (2011) Incidence, epidemiology, and prognosis of residual pulmonary hypertension after mitral valve repair for degenerative mitral regurgitation. Am J Cardiol 107: 755-760.

30. Rawczyńska-Englert I, Korewicki J, Purzycki Z, Abramczuk E, Sitkowski W, et al. (1992) Analysis of remission of pulmonary hypertension after mitral valve replacement. Prz Lek 49: 302-305.

31. Fernandes JL, Sampaio RO, Brandão CM, Accorsi TA, Cardoso LF, et al (2011) Comparison of inhaled nitric oxide versus oxygen on hemodynamics in patients with mitral stenosis and severe pulmonary hypertension after mitral valve surgery. Am J Cardiol 107: 1040-1045.

32. Trachte AL, Lobato EB, Urdaneta F, Hess PJ, Klodell CT, et al. (2005) Oral sildenafil reduces pulmonary hypertension after cardiac surgery. Ann Thorac Surg 79: 194-197.

33. Hamamoto $\mathrm{H}$, Yamauchi $\mathrm{H}$, Yamaguchi $\mathrm{H}$ (2000) Mitral valve regurgitation associated with severe pulmonary hypertension successfully treated with nitric oxide gas: report of a case) Kyobu Geka 53: 384-386. 